\title{
Assesment of managerial behavior in the correction of ergonomic problems at an airport
}

\author{
Anderson N. Lima ${ }^{\mathrm{a}^{*}}$, Valéria B. Gomes ${ }^{\mathrm{a}}$ \\ ${ }^{a}$ Departamento de Engenharia Industrial,Faculdade de Engenharia,Universidade do Estado do Rio de Janeiro - \\ Brazil
}

\begin{abstract}
As demanded at Collective Employment Agreement (CEA), three Ergonomic assessment of work (AEW) where made into an airport from a big Brazilian city (in particular, at the flight tower), with a 2 years interval between them. The objective was to produce a report pointing out problems and solutions. At the third time (2010), were verified that the work conditions where almost the same from 2006 and 2008, although all recommendations made in the reports. This work presents how the AET Team worked with this situation. At the third AEW, due the lack of real changes and the necessity of a report, the strategy was to know how workers where dealing with the complains and constraint detected at the previous reports, and how it interfere in abnormal or danger situations. Trying to explain this organizational phenomenon, we resort to Resilience Engineering to understand how those f/actors played to achieve its objectives.
\end{abstract}

Keywords: Ergonomics Assesment of Work, Resilience Engineering, Airport Management

\section{1 - Introduction}

In 2006, an unusual sequence of minor incidents and major accidents involving air transport in Brazil demanded federal intervention. The media grouped all those events, from postponed flights to two plane crashes as "Aerial Blackout" or "Aerial Chaos". At first glance, some of these negative events aren't related, but the only undeniable fact that we want to emphasize is that it forced all airport managers to deal with the rising demand of better work conditions for flight controllers. [4]

In this context, we expose the assessment made in a Brazilian airport, located in Rio de Janeiro. The Collective Employment Agreement (CEA) from the aerial traffic workers determined that Ergonomics Assessment of Work (EAW) should be performed, in order to provide professional and external help and turn them into efforts to achieve better work conditions.[8]

An Ergonomics Assessment of Work was performed in 2006, 2008 and 2010, in almost all job positions from the airport. Here, we will discuss only two job positions: the air controller and the airport operator. The air controller position had been assessed in 2008 and 2010, as well as the airport operator position in 2006, 2008 and 2010.

Based on these EAWs, we try to understand the behavior of the airport managers towards the results given. This is made under the concepts of the Resilience Engineering (ER), a paradigm for safety management designed for organizations that deals with potential hazards.

The article herein is structured as it follows: The methodology is described in the second section, the theoretical reference for the AEW and ER is presented in the third section. The characterization of the job positions are explained at section four The synthesized results from the EAWs are presented in the fifth section. At the sixth section, we compare

*email: andersonlima79@gmail.com 
ergonomic indexes taken from this EAW Conclusions are presented in the seventh section, as well as future studies and recommendations.

\section{2 - Methodology}

The previous results of the EAWs attracted the attention of the team that had performed them, since it goes against its objective: There was no significant improvement on the work conditions in almost 6 years. Due to this fact, we tried to understand the managerial behavior that contributed to these results. Hence, after a brief description of the job positions, we construct a theoretical base in ergonomics and resilience engineering. We use the first one to explain the methodology used to perform the assessment, as well as its objectives. The second is used as a reference to assess the managerial behavior when correcting ergonomics problems. Resilience engineering was chosen due to its compatibility with the safety demands of an airport in all aspects, not to mention the experience of the writers about the subject.

Hence, the present article is based in two main methodologies: The Ergonomics Assessment of Work, as described by Mont'alvão e Moraes [6] and a comparison between the resilience engineering concepts from Chiavenato[15]; Woods e Wreathall[18], and results achieved by Ballardin and Guimarães[19], the relative indexes shown by the EAW and its assessment. Then, we make our considerations to evaluate if this concept is met by the organization.

\section{3 - Theoretical reference}

\section{1 - Ergonomics assessment of work:}

Ergonomics (also called human factors) is defined as:

"Ergonomics (or human factors) is the scientific discipline concerned with the understanding of interactions among humans and other elements of a system, and the profession that applies theory, principles, data and methods to design in order to optimize human well-being and overall system performance.”(IEA, 2000).
Therefore, the Ergonomics Assessment of Work ${ }^{1}$ is a methodology to apply the objectives of the Ergonomics to a job position. In all EAWs performed, the methodology used is the one proposed by Mont'alvão e Moraes[6].

Many authors describe the differences between the Anglo-American ergonomics (also called human factors) and the European ergonomics (that designates itself as ergonomics). Despite the common object of study - man and his work - these approaches keep its particularities, being easily distinguished.

The human factors are focused on interfacial problems of the man-machine system. Generally it is achieved by resizing the workstation, improving the acquisition of information from meters and better control manipulation. Mainly physiology and anatomy are used to design the physical interfaces, and psychology and semiotics for information acquisition and processing.

The European Ergonomics has a more holistic approach. It aims at the singularities of an activity, studying the man, tools and the activity as a whole system, with a more sociological contextualization. It is less concerned with physiological and anthropological issues, and its goal is to describe and optimize the interaction between the operator and his task, directly assessing them by observing the real activity.[6]

Both logics are way too different to converge into a single description, but both have their own potentialities; Montalvão and Moraes described the methodology articulating both theoretical references, with the objective of extracting from each one the best contribution.

There are 5 stages in the methodology described by Mont'alvão e Moraes [6]:

- Appreciation: A preliminary study, with interviews, systematic observation, registers by photograph and recordings. All problems are identified and registered.

- Diagnosis: A detailed study of the problems registered in the appreciation stage. In the first stage, the ergonomist focus his/her attention on all aspects of the activity at the same time. Now, it is possible to make an in-depth assessment, with measures, structured interviews, sequence/duration of postures and more particular considerations about

1 The term used by the authors is Intervenção Ergonômica "Ergonomics Intervention, literally. We use the term EAW because is the term more commonly used on papers written in English. 
organizational, environmental, technological and physical conditions.

At this point, all problems which were identified during the appreciation stage are either confirmed or refuted. This result is presented at the "ergonomics problems table", where literature revision and norm adequacy are used to support the proposed improvements.

- Design: Tools, equipments, organizational procedures and more are designed to meet the worker demands. So the improvement gets its representation in the real world, and can be tested and validated in the next stage.

- Evaluation: The workers evaluate the improvement, so it is possible for them to accept, propose adjustments or refute the proposal.

- Detailing: The proposals validated by the workers and the company are detailed, taking into account the project costs, technological priorities, installed capacity, technical solutions available and other strategic aspects.

Not all stages are necessary to elaborate an assessment. In our case, the stages performed were: Appreciation, Diagnosis, Design and Evaluation.[6]

\section{2-Resilience:}

This word has the Latin radical resilio which means to return to a previous condition. It is used by physics and traditional engineering to describe the capacity of a body to return to a previous state, after suffering deformations caused by an applied force. By analogy, the term is used to describe the same behavior, but not from bodies against forces. It describes how a person can deal in dangerous situations, or how a city would manage its civil resources after an earthquake, or an ecosystem capacity to act with pollution.[2,10,21].

In our case, we will use the resilience concept applied to an organization. Wreathal [18] said that:

"Resilience is the ability of an organization (system) to keep, or recover quickly to, a stable state, allowing it to continue operations during and after a major mishap or in presence of continuous significant stress"
This property is important for organizations which work under hazardous conditions, such as refineries, nuclear plants, airports. Since a mishap could cause a major incident with great loss of human, environmental and economical resources, these systems should deal with any interference given and return to its previous state without allowing the worst to happen.[18]

\section{3 - Resilience engineering:}

It can be understood as a tool for safety management. Its objective is to improve the resilience of a system, so it becomes more resistant when facing problems, and even prevents incidents from happening.[20].It is considered an application of the cognitive systems engineering (CSE) in the field of workplace health and safety. [23].

One important aspect from the RE is having proactive stance when facing the possibilities of negative events. Having defined the indexes, it seeks to improve them, which consequently increases the system performance in the face of adversity. Moreover, it is based on the CSE, and it considers the particular dynamics of a sociotechnical system, and seeks to eliminate the various causes that may culminate in an incident. [1,11,19]

\section{4 - Characterization of the job positions}

\section{1 - The flight controller:}

In terms of civil aviation, the traffic control is essential to keep the safety of the aircrafts. As the operator of this system, the flight controller articulates instructions with the aircraft pilots, so the flight plans previously executed can be followed with minor deviations, except when necessary.

The main goal is to keep the aircraft in safe routes, avoiding its collision with another aircraft or any other natural obstacles. The work is done in real time, based on the flight plan, which is presented to the controller before an aircraft enters his/her area of responsibility. The inherent complexity of the activity is such that, even if it works under the exact protocol, each operation has its unique characteristics.

As the main tools, the flight operators use the radar and the radio. The radar displays real-time information about aircrafts flying over their area of responsibility and its outskirts. It displays the aircraft prefix (used as the identification), speed, direction, 
origin and destiny, and also the proximity to another aircraft - sometimes in meters or in remaining time for collision. The radio allows voice communication with the aircraft, so it enables the air controller to exchange information directly with the aircraft.

Despite the previous planning, routes are evaluated in real time, all the time, because deviations are common, and they can lead to potentially dangerous routes. Once the controller identifies this possibility, he/she makes contact with the aircraft involved, so that the routes are changed and there is no likelihood of collision. The processing of erroneous information exchanged during this transaction could lead to accidents.[3,7]

Automation of certain necessary tasks for flight control results in a decrease in the cognitive load, resulting in less tiring and faster operations. However, this feature turns out not to use certain basic skills as often as necessary to ensure that they continue to be applied in adverse situations. Despite the gain in performance indicated by analysis made in relative short periods, it should be taken into consideration that these technologies tend to reduce the worker's knowledge base over the years, which has direct influence on the factor of human error. $[9,17]$

The dynamics of the flight traffic control demands that problems must be solved almost immediately, or an accident might happen. Unlike an industrial plant, there is no shutdown button. It makes the cognitive processes more influential at the activity. [7]

During the assessment, some constraints were detected, and some will be shown to illustrate the work conditions:

- Night work shift: Landings, takeoffs and flights occur at all times, which require a flight control acting 24/7.

- Real Time Monitoring: within a densely occupied airspace, a small deviation in one of the routes may result in the need for immediate intervention. Therefore, it is necessary to keep the evaluation of the routes at all times.

- Language Barrier: Although the English language is accepted as default for the communication between actors with different native languages, it is not uncommon to have difficulty in transmitting messages.

- High load of information processing: in order to be done safely, a modified route involves the evaluation of several variables, its effects on other routes, as well as communication with the aircraft. Although there are softwares that help in decision making, the cognitive load involved causes stress.

- Overload peaks: The unpredictability of events that may cause major changes in pre-established routes complicates scaling the workload per controller, which ultimately generates overload peaks. - Sense of responsibility: An error can cause the loss of several lives and/or high financial loss, which might become a stress factor.

\section{2 - Airport operators}

There is few specialized literature regarding the sector of airport operations and this fact has a great impact on airport service as a whole. They are the professionals who operate the aircraft taxiing. They act after the plane is already on the ground, but still, can expose customers to hazardous situations. It is their responsibility to define the path that the plane should follow when taxiing, and ensure that this path is free of cars, pedestrians or another aircraft, given the limited maneuverability of the aircraft on the ground. Planning errors can also cause delays in flights and landings, which also directly influences the perceived quality of the service provided by the airport and can hamper the scheduling landings, requiring reprogramming of routes previously defined by flight controllers.

\section{5 - Resumed EAW results}

Since it is a large document, the whole AEW will not be presented herein. Instead, some ergonomics indexes will be presented to contextualize the work conditions assessed.

The Airport is situated at Rio de Janeiro,Brazil, atteding to domestic flights.

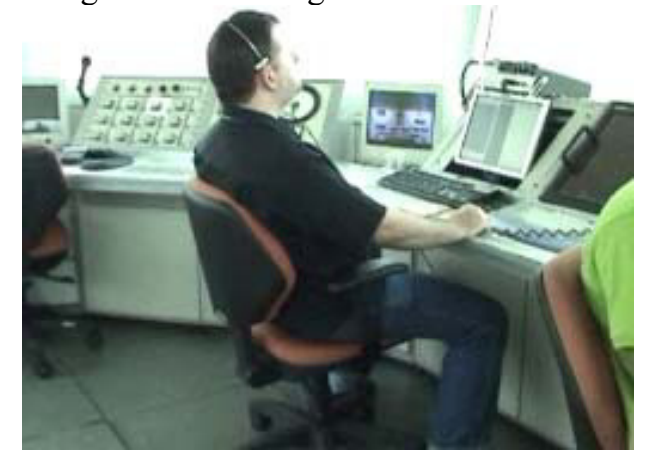

Fig. 1 - Workstation 
At the Control Tower, there was not enough space to accommodate the worker's legs. As a result of this, some bad postures were identified, with extension of the vertebral column and flexion of the thoracic column. Some chairs did not have lumbar support and/or elbow support.

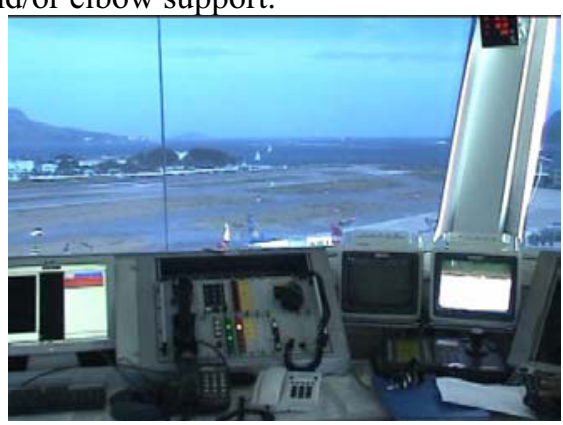

Fig2 - Runway view

Lack of visibility of the runway by the controllers could jeopardize the decision-making process.

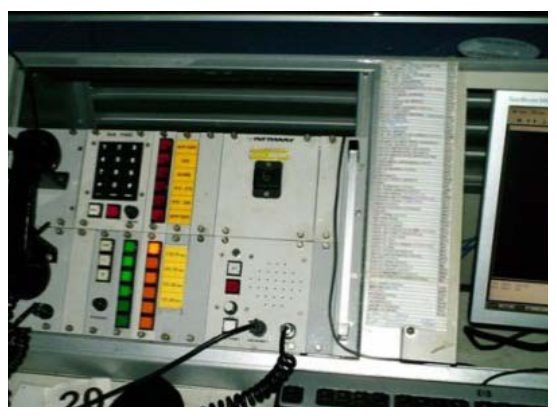

Fig3 - Comunication devices

Information overload on the equipment set in small print, disorganized topics, causing problems to read the information displayed and hindering the decision making process.

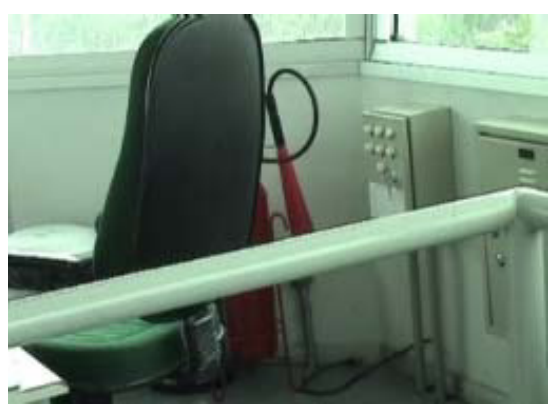

Fig.4 - Fire Extinguisher
Limited access to the fire extinguisher.

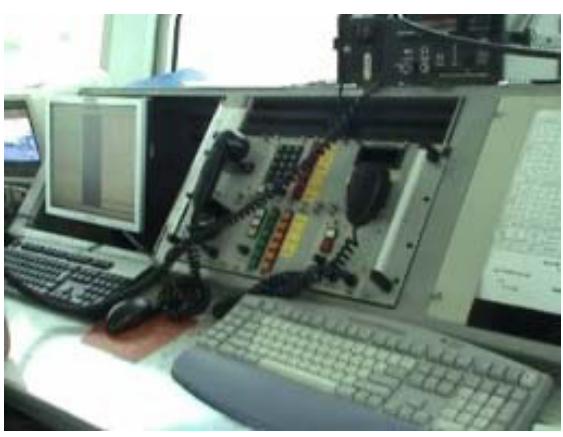

Fig 5 - Desktop view

Excess of devices, without proper space.

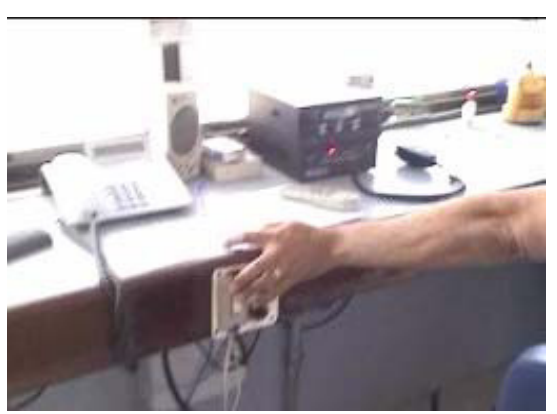

Fig 5 - Desktop detail

Biomechanical constraints when pushing controls that are outside the comfort zone.

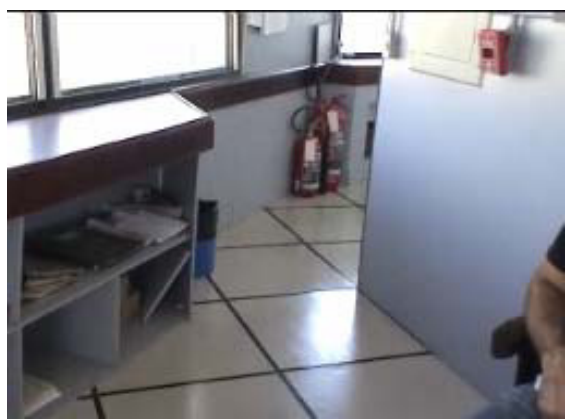

Fig 6 - A passage to the workstation

A narrow passage which hinders the access of wheelchair users and people with limited movement conditions. 


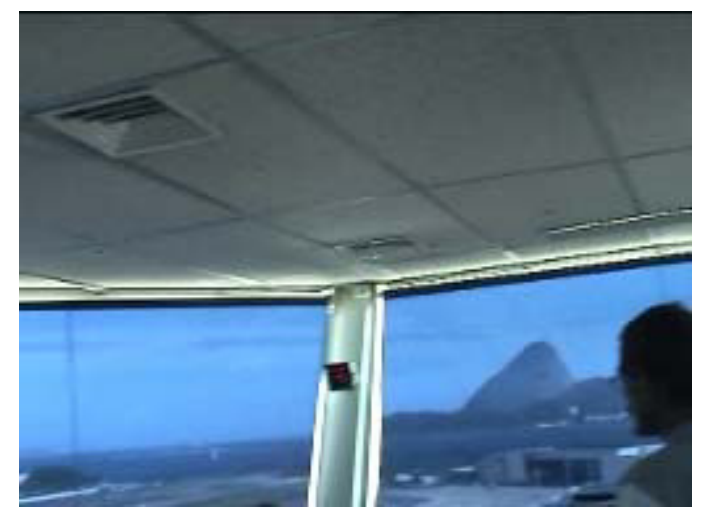

Fig $7-\mathrm{CT}$ roof

There is no direct light at the desk of the workstation.

All EAW recommended solutions for the problems identified. As said before, no significative change of the conditions of work were done in order to solve the indexed problems. This was an odd situation, because both operator and managers urged for better and safer work conditions. Then, the EAW team indicated the need to assess this situation.

There were several changes in organizational structure, reallocation of employees, manager changes and increased demand, at an environment that was supposed to maintain the predictability and regularity

\section{6 - Results analysis}

To compare the results, we classified the E.R. concepts and the ergonomics indexes as five dimensions: Leadership, Culture, Individuals, Systems and Work Environment. Each dimension will be presented on 5 levels: Following the E.R. guidelines of i)Chiavenato[15], ii)Wreathall[18], iii) the results achieved by Ballardin and Guimarães[19], iv) the relative indexes shown by the EAW and v) our considerations to evaluate if this concept is met by the organization. Due complex nature, of the activity we expect to achieve a coherent result alignin our answer with more than one point of view.

\section{1 - Leadership}

i) Resilience begins when the company's leadership sets priorities, allocates resources and makes commitments to establish organizational resilience throughout the enterprise.
The leadership needs to achieve a balance between taking risks and containing risks to ensure innovation, within a context of prudent risk minimization.

Ii) The commitment of the management to maintain a balance between productivity and safety.

iii) The observation proved that there are jobs with a large workload, as well as other sectors that are idle. This inequality has been mentioned several times by workers when they talked about the time interval (break) between different employees. Better distribution of the workload is important not only to establish a fair balance of work, but also because, the fatigue and performance of a number of activities greater than the capacity of workers may contribute to the occurrence of ccidents; [13]

iv) The way that managers set priorities, allocate resources and set up appointments in the annual planning considering the ergonomics recommendations identified in the 2006 and 2008 EAW report.

v) The results of ergonomics assessments and recommendations were presented to all managers in a joint meeting encouraging the development and implementation of an action plan for each department. Changes in the organizational structure and managers in a short time discouraged the continued application of the results. This hindered the achievement of a balance between taking risks and containing risks to ensure innovation, within a context of prudent risk minimization

\section{$6.2-$ Culture}

i) The second component of organizational resilience is the organizational culture. A resilient culture is built on principles of empowerment of people, purpose and confidence. Networks of people, who selforganize into communities of practice, learning to participate, lead and organize virtual teams. In these networks with connected and empowered people, lies the basic form of what is called Resilient Virtual Organization. The resilient organizational culture has a strong sense of purpose cascading up and down the organization that aligns individual goals, group and organizational as a continuum.

ii) The culture of incident reports, FAIR culture.

iii) Reports of accidents with the effective operators are performed by a team of the health and safety department of the company and its conclusions are communicated during the monthly operators meetings. However, it was observed that accidents and near misses that occur with drivers and 
subcontracted employees are not mapped and investigated with the same attention, but only as a way to comply with the norms. In both populations, although there is fear of punishment, since they are not acting with formal work contracts, which make this report to avoid accidents and even more often, near misses.

This difficulty has been cited previously in the literature by Van der Schaaf and Kansas [22], which describe the main causes of non-reporting near misses, fear of disciplinary action, the acceptance of danger, lack of awareness of the importance of reporting and the impression of wasting time for its completion. Therefore, one may assume that the resilience of the organization can be improved if the culture of reports changes;

iv) Beyond the changes proposed by the Collective Labor Agreement, identify if the flight controllers and airport operations workers were designed to change and trusted that they could occur, participating and spreading the improvements.

v) This aspect was impaired for the same reason above, clearly demonstrated among the flight controllers a climate that if the proposed improvements were implemented, it would be very difficult to occur, lacking sense of purpose cascading below and above organization by aligning individual goals, as a group and organizational continuum.

\section{3 - Individuals}

i) The core of organizational resilience lies in people. They should be properly selected, motivated, supported, equipped and led to overcome any obstacle or disaster. People need skills and competencies that produce behaviors to operate effectively in environments with rapidly changing scenarios and unstructured. At the same time, they must rely on support and services beyond organizational boundaries. The traditional HR department must transform itself into a virtual group that can support people regardless of time and space, wherever the service is needed.

ii) The culture of organizational learning.

iii) The organizational learning culture is one of the indexes with the largest number of aspects that can be evaluated considering the introduction of new technologies and the knowledge accumulated by members of the organization.

iv) Motivation, support, tools and leadership to overcome any obstacle or emergency. v) The motivation which led to the first ergonomics evaluation was not accompanied by concrete actions to equip the workers, despite the efforts of the managers. It was verified, however, that there was the conservation of individual skills and competencies that contribute to behaviors that determine the effective action in environments with rapidly changing scenarios and unstructured. The organization provides support by maintaining an antistress room.

\section{$6.4-$ Systems}

i) Organizations should be built on an infrastructure that enables connectivity and extensive amount of information. The premise is that the world's leading organizations are gaining agility and flexibility by combining a model workplace with a highly distributed infrastructure of information technology and extensive collaboration

ii) Tools and equipments that allows anticipation to correct possible near misses.

iii) The Resilience Engineering assumes that it is not possible to completely eliminate the variability, so one must look for ways to control it so they do not cause damage to the organization.

iv) Flexibility in the workplace with safety, comfort and connectivity.

v) Considering the nature of the activity described, the control tower is at a fixed location, privileged in the building, with wide visibility for the entire area to be observed. There are restrictions on the internal environment regarding the comfort of the flight controllers and distribution of technological devices and there are high connectivity demands of the task itself and constant evaluation of the safety and comfort of the workplace. Same applies for the Airport operation workers.

\section{7 - Conclusions}

As shown above, it was found that these five guidelines were not met satisfactorily, and then an ergonomics program was developed for the company along with the Human Resources Department, emphasizing these five guidelines and aiming at implementing the technical, administrative and training recommendations previously appointed and thoroughly discussed with the Managers and Flight Controllers/Airport ops workers. 
As future studies, is considered the construction of a more flexible framework, in order to be applied to a greater kind of cases, since this one was made for high hazard organizations.

\section{Acknowledgments}

We wish to express our appreciation for CEFEN Centro de Estudos da Faculdade de Engenharia da UERJ, the Management of FEN-Faculde de Engenharia da UERJ and the DEIN - Departamento de Engenharia Industrial for the support.

Gratefulness extended to Ms. Eliza Brossa for the fastest review of language ever.

\section{References}

[1] A. Blandford, D.Furniss, J. Back, , M. Hildebrandt, e H Broberg, A Resilience Markers Framework for Small Teams, Reliability Engineering and System Safety, 2010.

[2] A. C. Limongi-França , L. Barlach, S. Malvezzi, O Conceito de resiliência aplicado ao trabalho nas organizações, Interamerican Journal of Psychology,2008.pp 101-112.

[3] A. M. Viludich, Information Processing in Aviation, In: Human Factors In Aviation, por Eduardo Salas e Dan Maurino. San Diego,California, Academic Press, 2010.

[4] A. Matais, L. Marra, Controladores de tráfego aéreo se organizam e ameaçam greve branca, 2006. http://www1.folha.uol.com.br/folha/cotidiano/ult95u127520.s html

[5] A. Teperi,A. Leppanen, Managers' conceptions regarding human factors in air traffic management and in airports operations, Safety Science, 2010.

[6] A. M. Moraes, C. Mont'alvão, Moraes. Ergonomia Conceitos e Aplicacões. 4 ed. Rio de Janeiro: 2AB, 2010.

[7] B. Kirwan, H.W. Gibson,B. Hickling, Human error data collection as aprecursor to the development of a human reliability assessment capability in air traffic management, Reliability Engineering and System Safety,2007,pp.217-233.

[8] Brasil. Consolidação das Leis do Trabalho - Decreto-Lei N. ${ }^{\circ}$ 5.452, de $1^{\circ}$ de Maio de 1943 - Incluído pelo Decreto-lei ${ }^{\circ}$ 229, $\quad$ de $28.2 .1967 . \quad 1967$ http://www.planalto.gov.br/ccivil_03/decreto-lei/del5452.htm (acesso em 06 de Maio de 2011).

[9] C. L. R. Motta,F.R. Lapolli, J. O. Gomes, C. E. Tola,Metacognição como processo de aprendizagem visando a construção de respostas adaptativas em profissionais que atuam em sistemas complexos, In: 3RD CTA-DLR WORKSHOP ON DATA ANALYSIS \& FLIGH CONTROL, 2009.

[10] D. Amaratunga,R. Haigh, An integrative review of the built enviroment discipline's role in the development of the society's resilience to disasters, International Journal of Disaster Resilience in the built environment, 2010,pp.11-24.

[11] D. Woods, E. Hollnagel ,Cognitive Systems Engineering: New wine in new bottles., International Journal of ManMachine Studies, 1983,pp.583-600.
[12] D. Woods, E. Hollnagel,Prologue: Resilience Engineering Concepts, In: Resilience Engineering: Concepts and precepts, D. Woods, E. Hollnagel, Aldershot,UK, Ashgate, 2006.

[13] E. J. McCormick,M.S. Sanders, Human Factors in Engineering and Design, United States, McGraw-Hill,1993

[14] F. Gracia, M. Martínez-Córcoles, I. Tomás, J. M. Peiró,Leadership and employees' perceived safety behaviours in a nuclear power plant: A structural equation model, Safety Science, 2011

[15] I. Chiavenato, Você sabe o que é Resiliência?,Site do Administrador, http://www.portaladm.adm.br/Tga/tga21.htm

[16] I. J.L. Santos,M. C. R. Vidal, P.V.R. Carvalho, M. S. Santos, "Collective work and Resilience of Complex Systems." Journal of Loss Prevention in the Process Industries, 2009,pp.516-527.

[17] J. Reason, Modelling the basic error tendencies of human operators, Reliability Engineering and System Safety 22, 1988,pp:137-153.

[18] J. Wreathall, Properties of Resilient Organizations: An Initial View, In: Resilience Engineering: Concepts and precepts, D. Woods, E. Hollnagel, Aldershot,UK, Ashgate, 2006

[19] L. B. M. Guimarães, L. Ballardin, A Aplicaçao dos Princípios da Engenharia de Resiliência na Indústria de Distribuição de Derivados de Petróleo, XXVI ENEGEP, 2006.

[20] L. B. M. Guimarães, C. V. Vargas. A Engenharia de Resiliência e o Sistema de controle de Tráfego Aéreo, XXVI ENEGEP, 2006.

[21] L. Barlach, O que é resiliência humana? Uma contribuição para construção do conceito. Msc Thesys, Universidade de São Paulo, 2005.

[22] L.B. Kanse, T. Van Der Schaaf, Biases in Incident Reporting Databases: an empirical study in the chemical process industry. Safety Science, Amsterdam, v. 42, n. 1, 2004,pp. 5767

[23] M.F. Costella, Método de Avaliaçao de sistemas de gestão de segurança e saúde no trabalho (MASST) com enfoque na engenharia de resiliência. $\mathrm{PhD}$ Dissertation, Universidade Federal do Rio Grande do Sul, 2008. 